\title{
The confusion surrounding prostate cancer screening faced by family physicians
}

\author{
Nathan A. Hoag, MD; Alan I. So, MD, FRSCS
}

Department of Urologic Sciences, University of British Columbia, Vancouver, BC

See related article on page 188 .

Cite as: Can Urol Assoc J 2012;6(3):194-5. http://dx.doi.org/10.5489/cuaj.12123

$\mathrm{P}$ rimary care physicians, in the forefront of prostate cancer screening, are challenged with confusing and often conflicting guidelines. The lack of uniformity on the optimal prostate cancer screening recommendations stems from conflicting interpretations of the results of recent screening studies. Unfortunately, two large trials, initially planned to define the usefulness of screening, were both significantly flawed and provided conflicting results and further fueled the debate. ${ }^{1,2}$

Not surprisingly, these results have led to a lack of consensus on the best screening practices among various medical associations and guideline committees. The limitations of prostate-specific antigen (PSA) itself as a screening tool have precluded standardized and widely adopted guidelines from being developed to date. ${ }^{3}$ Several guidelines have been established; the American Urological Association and Canadian Urological Association favour the inclusion of PSA testing as a tool for prostate cancer screening, 4,5 while the Canadian Task Force on Preventative Health Care and the U.S Preventative Services Task Force (USPSTF) recommend against screening. ${ }^{6,7}$ These are in addition to provincial and advocacy organizations' recommendations - it is no wonder physicians and patients are confused.

Controversy surrounding optimal prostate cancer screening for primary care physicians was renewed with the recent publication of the USPSTF statement, which attracted considerable media attention. Their recommendations were against PSA-based screening for prostate cancer in all men. PSA screening was labelled a "Grade D" recommendation, which states that there is moderate or high certainty that PSA screening has no benefit, or that the harms outweigh any benefits. ${ }^{7}$
It is important to stress the results of the European Randomized Study of Screening for Prostate Cancer, considered the best PSA screening study to date. It was demonstrated that screening reduced the rate of prostate cancer death by $20 \%$, with additional two-year follow-up consolidating these findings. ${ }^{2,8}$ Being the largest trial to date and suffering fewer methodological limitations than its U.S. counterpart, this European study represents "level one" evidence that screening does reduce prostate cancer-specific mortality. It was proposed that the modest benefit conveyed should support

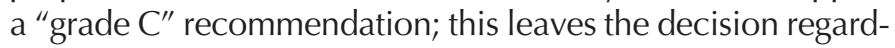
ing PSA screening to the patient and primary care physician. ${ }^{9}$

The results of the survey in this issue of CUAJ provide evidence to suggest that Ontario family physicians use their own management strategies in deciding whether to offer prostate cancer screening to their patients. ${ }^{10}$ As well, there is apparent heterogeneity in the use of screening, as well as in the attitudes concerning its value. Interestingly, although almost $80 \%$ screen for prostate cancer, a considerably lower percentage of family physicians believe that the benefits of screening outweigh its risks, which suggests that other patient factors prompt the decision to screen.

Obviously, a primary weakness of the paper is the poor response rate. The results do, however, provide a glimpse into the practice patterns of physicians directly involved in screening. It is likely that the results can be extrapolated to the rest of the country, as these findings have been corroborated by other papers addressing the same question in Newfoundland and British Columbia. ${ }^{11,12}$

Most importantly, the survey shows the need not only to provide clear and evidence-based guidelines, but also for better education on prostate cancer screening for family physicians. A significant onus of responsibility for this lies with our own association and members. It highlights the importance of relaying our own CUA guidelines to family physicians, and educating them regarding the evidence and considerations surrounding prostate cancer screening. 
Competing interests: None declared.

This paper has been peer-reviewed.

\section{References}

1. Andriole GL, Grubb RL, Buys SS, et al. Mortality results from a randomized prostate-cancer screening trial. N Engl J Med 2009;360:1310-9. htrp://dx.doi.org/10.1056/NEJMoa0810696

2. Schröder FH, Hugosson J, Roobol MJ, et al. Screening and prostate-cancer mortality in a randomized European study. N Engl J Med 2009;360:1320-8. http://dx.doi.org/10.1056/NEJMoo0810084

3. Brett AS, Ablin RJ. Prostate-cancer screening-What the U.S. Preventative Services Task Force left out. N Engl J Med 2011;365:1949-51. http://dx.doi.org/10.1056/NEJMp1112191

4. Greene KL, ALbertsen PC, Babaian RJ, et al. Prostate specific antigen best practice statement: 2009 update. J Urol 2009;182:2232-41. http://dx.doi.org/10.1016/i.juro.2009.07.093

5. Izawa Jl, Klotz L, Siemens DR, et al. Prostate cancer screening: Canadian guidelines 2011. Can Urol Assoc J 2011;5:235-40. http://dx.doi.org/10.5489/cuaj.11134
6. Feightner JW. Screening for prostate cancer. In: Canadian Task Force on the Periodic Health Examination. Canadian Guide to Clinical Preventative Health Care. Ottawa: Health Canada;1994:812-23.

7. U.S. Preventive Services Task Force. Screening for Prostate Cancer: Draft Recommendation Statement. http://www.uspreventiveservicestaskforce.org/uspsffl2/prostate/draftrec3.htm (Accessed May 9, 2012).

8. Schröder FH, Hugosson J, Roobol MJ, et al. Prostate-cancer mortality at 11 years of follow-up. N Engl J Med 2012;366:981-90. http://dx.doi.org/10.1056/NEJMoal 113135

9. McNaughton-Collins MF, Barry MJ. One man at a time- Resolving the PSA controversy. N Engl J Med 2011;365:1951-3. htrp://dx.doi.org/10.1056/NEJMp1111894

10. Allard CB, Lusis J, Dason $S$, et al. Prostate cancer screening: Attitudes and practices of family physicians in Ontario. Can Urol Assoc J 2012;6:188-93. http://dx.doi.org/10.5489/cuaj.11290

11. Curran V, Solberg $S$, Matthews $M$, et al. Prostate cancer screening attitudes and continuing education needs of primary care physicians. J Cancer Educ 2005;20:162-6. http://dx.doi.org/10.1207/ s15430154jec2003_10

12. Hoag NA, Davidson RA, Pommerville PJ. Prostate cancer screening practices and attitudes among primary care physicians in Victoria, British Columbia. Br Columbia Med J 2008:50:456-60.

Correspondence: Dr. Alan So, 6th Floor, 2775 Laurel St., Vancouver, BC V5Z 1M9; alan.so@ubc.ca 